\title{
Prognostic prediction of a 12-methylation gene-based risk score system on pancreatic adenocarcinoma
}

\author{
DAOQIN DOU ${ }^{1}$, SHAOHUA YANG ${ }^{1}$ and JIREN ZHANG ${ }^{2}$ \\ ${ }^{1}$ Radiotherapy Department of Shenzhen Bao'an People's Hospital, Shenzhen, Guangdong 518101; ${ }^{2}$ Oncology \\ Department of Zhujiang Hospital of Southern Medical University, Guangzhou, Guangdong 510280, P.R. China
}

Received March 17, 2019; Accepted January 13, 2020

DOI: $10.3892 /$ ol.2020.11575

\begin{abstract}
Pancreatic adenocarcinoma (PAAD) accounts for $\sim 85 \%$ of all pancreatic cancer cases and is associated with a less favorable prognosis. Aberrant DNA methylation may influence the progression of PAAD by inducing abnormal gene expression. Methylation data of PAAD samples with prognosis information were obtained from The Cancer Genome Atlas (training set) and European Bioinformatics Institute Array Express databases (validation sets). Using the limma package, the differentially methylated genes in the training dataset were screened. Combined with the Weighted Gene Co-expression Network Analysis package, the co-methylated genes in key modules were identified. Then, a cor.test function in $\mathrm{R}$ software was applied to explore the functions of key the methylated genes. Correlation analyses of the expression levels and methylation levels of key methylated genes were performed, followed by identification of methylated genes associated with prognosis using Univariate Cox regression analysis. The optimal combination of prognosis related methylated genes was determined using a Cox-Proportional Hazards (Cox-PH) model. Subsequently, the risk score prognostic prediction system was constructed by combining the Cox-PH prognosis coefficients of the selected optimized genes. Based on the constructed risk score system, samples in all datasets were divided into high and low risk samples and the survival status was compared using survival curves. Furthermore, the correlation between independent prognostic factors and the risk score system was determined using the survival package. A total of 50 genes associated with prognosis of PAAD and a 12-gene optimal combination were obtained, including: CCAAT/enhancer binding protein $\alpha$, histone cluster $1 \mathrm{H} 4 \mathrm{E}$, STAM binding protein-like 1, phospholipase D3, centrosomal
\end{abstract}

Correspondence to: Dr Jiren Zhang, Oncology Department of Zhujiang Hospital of Southern Medical University, 253 Industrial Boulevard, Guangzhou, Guangdong 510280, P.R. China

E-mail: jriverz@sina.com

Key words: pancreatic adenocarcinoma, differentially methylated genes, weighted gene co-expression network analysis, correlation analysis, risk score system protein 55, ssDNA binding protein 4, glutamate AMPA receptor subunit 1 , switch-associated protein 70 , adenylate-cyclase activating polypeptide 1 receptor 1 , yippee-like 3 , homeobox $\mathrm{C} 4$ and insulin-like growth factor binding protein 1 . Subsequently, a risk score prognostic prediction system of these 12 genes was constructed and validated. In addition, pathological $\mathrm{N}$ category, radiotherapy and risk status were identified as independent prognostic factors. Overall, the risk score prognostic prediction system constructed in the present study may be effective for predicting the prognosis of patients with PAAD.

\section{Introduction}

Pancreatic cancer (PC) is primarily associated with diabetes, obesity, smoking and genetic conditions, such as germline pathogenic variants and somatic pathogenic variants in DNA damage repair (DDR) genes $(1,2)$. Jaundice, weight reduction, back or abdominal pain, deep-colored urine, pale-colored stools and anorexia are the typical symptoms (3). However, at diagnosis, the cancer has usually metastasized $(4,5)$. The mortality rate of PC is high and there were 411,600 PC-associated deaths globally in 2015 (6). Pancreatic adenocarcinoma (PAAD) is a common type of PC, accounting for $\sim 85 \%$ of all PC cases (7). The survival rate of PAAD is very low and the 5-year survival rate was $5 \%$ in 2015 (8). A few prognostic indicators are now available for PC, such as C-reactive protein/albumin ratio and neutrophil/lymphocytes ratio $(9,10)$. Therefore, it is of great importance to investigate the prognostic factors of PAAD for improved prediction.

It has been hypothesized that DNA methylation may provide a link between environmental factors contributing to cancer development (11). The stability of the genome and gene expression levels are primarily maintained by a pre-determined pattern of DNA methylation (12). It has been reported that DNA hypermethylation has prognostic value and acts as independent predictor of survival in other cancer types, such as head and neck cancer (13). A previous study reported an association between abnormal methylation of the Reprimo gene and genetic instability and poor survival following surgical resection in patients with PC (14). Hypermethylation of Cyclin D2 is also frequently observed in PC (15). Meanwhile, another study reported a significant difference in the hypermethylation frequency of ALX4, BNC1, HIC1, SEPT9V2,SST, TFPI2 and TAC1 between PAAD samples of stage I, II, III and IV, and these genes are significantly associated with distant metastasis of PAAD (16). 
A number of clinical markers of PAAD survival have been recognized, including stage at diagnosis, grading and performance status and the treatment received, such as resection versus no resection and chemotherapy vs. no chemotherapy (17-20). It has also been reported that obesity and smoking are associated with a less favorable prognosis of PC (21). Cigarette smoking is associated with the development of $20 \%$ of PC cases and is therefore a consistent risk factor (22). Bioinformatic databases may serve as a valuable tool to further our understanding of the molecular mechanisms underpinning the prognosis of patients with cancer.

The present study aimed to explore the aberrant methylation of genes associated with prognosis of patients with PAAD. The methylation data of genes associated with PAAD were obtained from The Cancer Genome Atlas (TCGA) database and screened for differentially methylated genes (DMGs) associated with prognosis. Subsequently, these data were used to construct a risk score system, which may be effective in predicting the prognosis of patients with PAAD.

\section{Materials and methods}

Datasets. The methylation data for the training dataset was obtained from the TGCA database (accessed on 5th June 2018; cancer.gov/tcga), which were based on the Illumina Infinium Human Methylation 450 BeadChip platform. There were a total of 184 samples, 168 of which included prognostic information [mean age, 64.89 \pm 11.24 years (range: 40-88); male: Female, 94/75; average overall survival time, 17.09 $\$ 15.22$ months; death: Survival, 88/80]. The methylation data for the validation training set was obtained from the European Bioinformatics Institute ArrayExpress database (ebi.ac.uk/arrayexpress/), specifically the E-MTAB-5008 and E-MTAB-5571 datasets. The E-MTAB-5008 dataset consisted of 29 PAAD samples with prognostic information and the E-MTAB-5571 dataset consisted of 24 PAAD samples which prognostic information. Both of these datasets were sequenced on the platform of Illumina Infinium Human Methylation 450 BeadChip.

Screening of DMGs. To screen genes associated with PAAD prognosis, samples in the TCGA dataset were divided into less favorable prognosis (defined as a survival time $<6$ months and death) and more favorable prognosis (defined as survival time $>24$ months or alive) groups based on a previously described grouping method (23). The methylation loci of genes associated with PAAD prognosis were annotated and combined with the platform annotation information on the Illumina Infinium Human Methylation 450 BeadChip platform and the loci within $\mathrm{CpG}$ islands of the genes were selected and used for the following analysis. Using the limma package in $\mathrm{R}$ (version 3.34.7) (24), the DMGs between the less favorable prognosis and more favorable prognosis groups were screened according to the following criteria: Ilog fold changel $>0.263$ and false discovery rate $(\mathrm{FDR})<0.05$. Then, the Kernel density curve of the DMGs was generated by calculating the Log 2 (FC).

Identification of co-methylated genes based on Weighted Gene Co-expression Network Analysis (WGCNA). Co-methylation analysis using the WGCNA package (version 1.63) (25) in R was performed on genes located in $\mathrm{CpG}$ islands to identify differentially methylated $\mathrm{CpG}$ genes (DMCpGs). The sets of $\mathrm{CpG}$ genes with highly related methylation levels under the same biological process or in different tissues were considered as modules. The modules which had a significant association with the methylation levels were identified. The DMCpGs were mapped to the modules and the significant enrichment parameters and fold enrichment were calculated using a hypergeometric test (26). The DMCpGs enriched modules were screened under the following criteria: $\mathrm{P}<0.05$ and a fold enrichment value of $>1$ was considered to indicate a statistically significant difference. Genes in DMCpGs enriched modules were recognized as key methylation genes and were analyzed using Gene Ontology (GO) enrichment analysis (27) using the Database for Annotation, Visualization and Integrated Discovery (version 6.8) (28).

To meet scale-free network distribution, the weighting parameter 'power' in WGCNA algorithm was explored. When the square of the correlation coefficient between $\log (\mathrm{k})$ and $\log [\mathrm{p}(\mathrm{k})]$ reached 0.9 , the corresponding value of parameter 'power' (power=7) was selected. Under power=7, the mean connectivity of genes was calculated to be 1 . Subsequently, the adjacency matrix elements were serialized, and the topological overlap matrix was calculated to evaluate the correlation of gene methylation levels and obtain a system clustering tree. According to the standards of hybrid dynamic shear tree, pruning height (cutHeight) and the minimum number of module genes (minSize) separately were set as 0.95 and 50 .

Correlation analysis for the expression levels and methylation levels of key methylated genes. The expression and methylation levels of key methylation genes in matched training PAAD samples were collected and correlation analysis was performed. Pearson correlation coefficients (PCCs) were calculated and the cor.test function (stat.ethz.ch/R-manual/ $\mathrm{R}$-devel/library/stats/html/cor.test.html) in $\mathrm{R}$ Software was used $(29,30)$. PCCs of single genes were also calculated and the genes with a negative correlation between expression level and methylation level were selected as key methylation genes for subsequent analyses. $\mathrm{P}<0.05$ was considered to indicate a statistically significant difference.

Identification of the methylated genes associated with prognosis. Key methylation genes with a negative correlation between expression level and methylation level were further analyzed for prognosis associated genes. Univariate Cox regression analysis was performed to identify prognosis associated methylation genes using the survival package (version 2.41-1) in $\mathrm{R}(31) . \mathrm{P}<0.05$ was considered to indicate a statistically significant difference.

Construction of risk score prognostic prediction system. The optimal combination of prognosis related methylation genes was screened using the Cox-Proportional Hazards (Cox-PH) model using the penalized package (version 0.9-50) in $\mathrm{R}(32)$. The optimal parameter of 'lambda' in the Cox-PH model was calculated through 1,000 cross-validation likelihoods (cvl) (33).

The risk score prognostic prediction system was constructed combining the Cox-PH prognosis coefficients and methylation levels of the selected optimized genes. The resultant formula

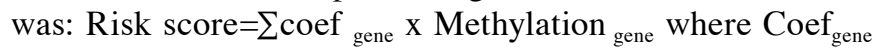


A
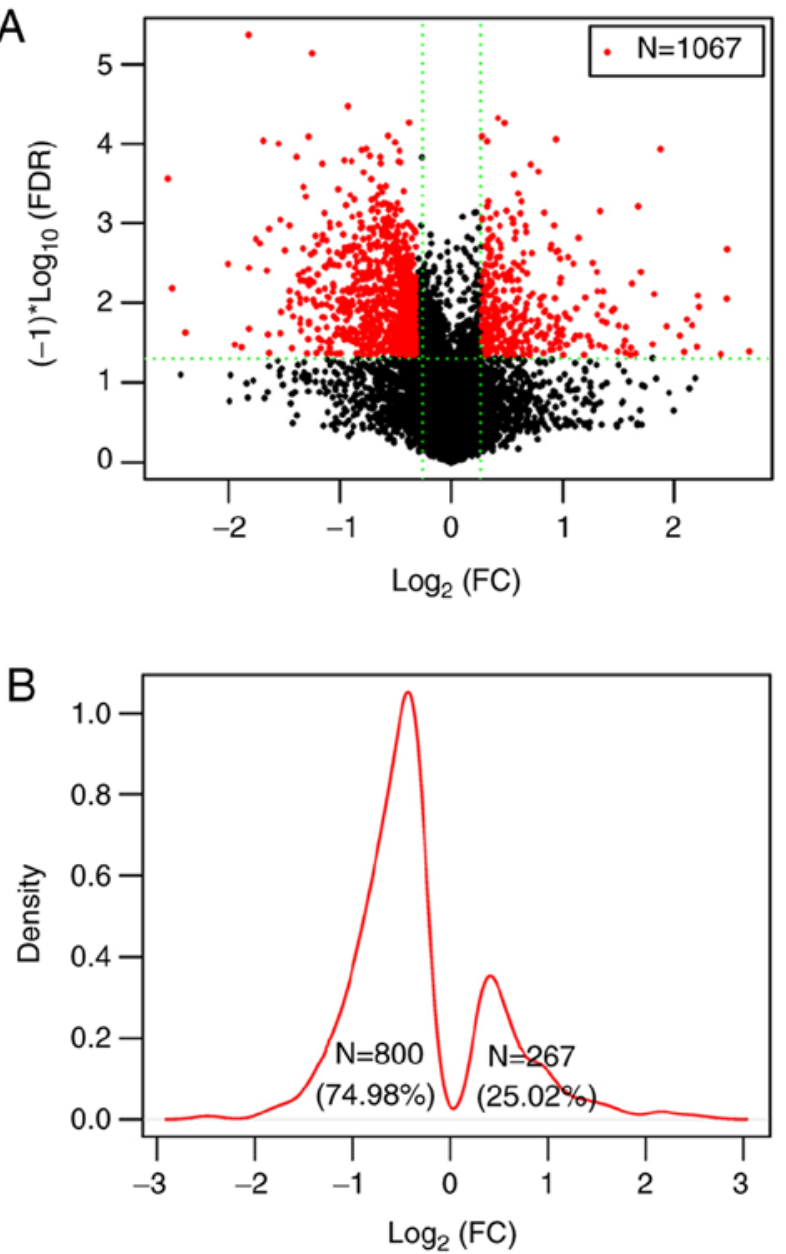

C
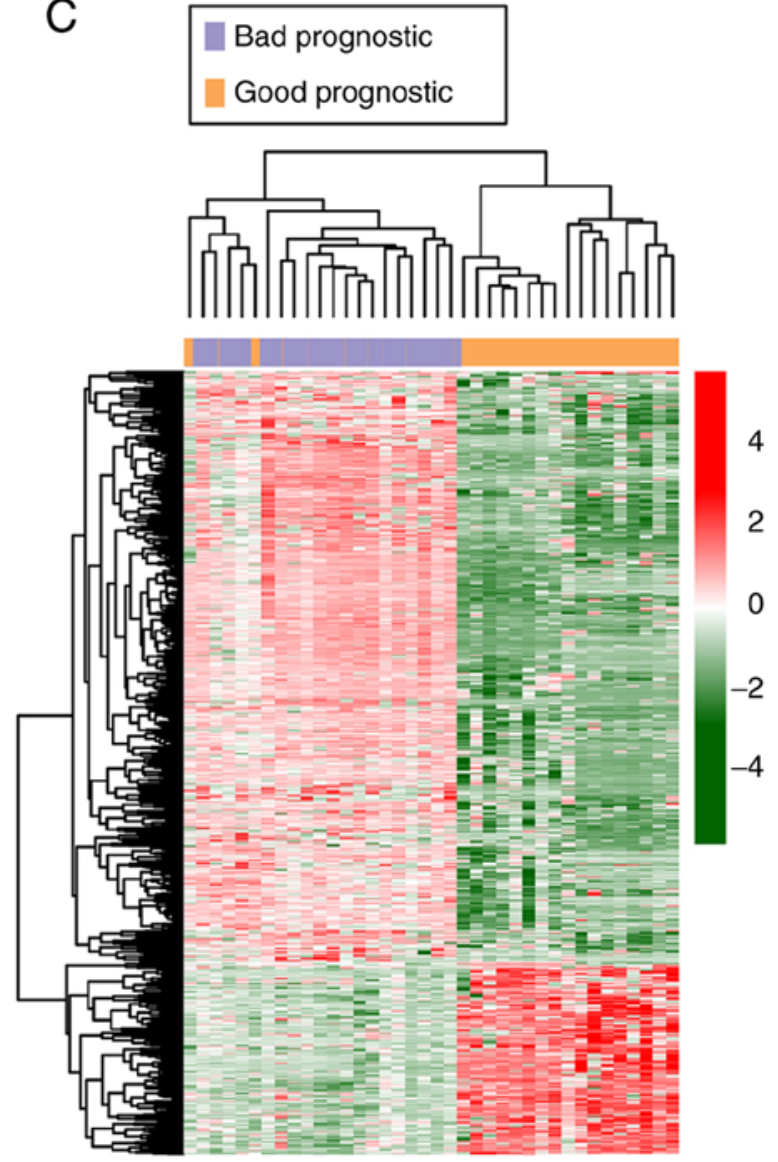

Figure 1. Volcano plot, density curve and cluster heatmap of DMGs. (A) Volcano plot showing the FC of each identified gene. Red dots, DMGs; horizontal dashed line, FDR <0.05; vertical dashed lines, $\log \mathrm{FCl}>0.263$. (B) Kernel density curve showing that $74.98 \%$ of the DMGs are significant hypomethylated in the good prognostic group. (C) Bidirectional hierarchical cluster heatmap. Orange and purple samples strips separately represent the samples in good and bad prognostic groups, respectively; color changes from green to red represent methylation level changes from low to high, respectively. DMGs, differentially methylated genes; FDR, false discovery rate; FC, fold change.

and Methylation gene $_{\text {represented regression coefficient and gene }}$ methylation levels, respectively.

The risk scores of samples in the TCGA, E-MTAB-5008 and E-MTAB-5571 datasets were calculated and stratified into high and low risk groups according to the median risk scores. Kaplan-Meier (KM) survival curves (34) of the high and low samples were plotted using the survival package, which were compared with the prognosis of all samples. The area under the receiver operating characteristic (ROC) curve (AUC) was compared, also using the survival package.

Correlation analysis between independent prognostic factors and risk score prognostic prediction system. Using the Cox regression analysis in the survival package (31), independent clinical prognostic factors were screened. Next, the relations between collected factors and the risk score prognostic prediction system were analyzed using KM curves.

\section{Results}

Screening of DMGs. Median survival time of samples in the training datasets was $17.09 \pm 15.22$ months, which is consistent with the time reported in PC (35). There were 13,903 methylation sites containing $\mathrm{CpG}$ islands in the training dataset. In TCGA training dataset, based on the predefined method for grouping, each less favorable and more favorable prognosis group had 19 samples, and a total of 1,067 DMGs between the two groups were identified (Fig. 1).

As shown in the $\log 2$ Kernel density curve of the DMGs, $74.98 \%(800 / 1,067)$ of DMGs were significantly hypomethylated and $25.02 \%(267 / 1,067)$ were significantly hypermethylated in the good prognostic group (Fig. 1B). The cluster heatmap of the DMGs suggested that the samples with different prognoses in the TCGA dataset exhibited different methylation levels (Fig. 1C). Furthermore, as the feature factors had different weights in the calculation process for heatmap analysis, there was a slight crossover between good and bad prognosis samples.

Among the CpGs in the 1,067 DMGs, 309, 321, 118, 44, 185 and 90 CpGs were separately located in transcription start site areas, body areas, 5'untranslated regions (UTR), 3'UTR regions, promoter regions and the first exon regions (data not shown). The top 20 DMGs with smaller FDR values were screened and presented in Table I. 


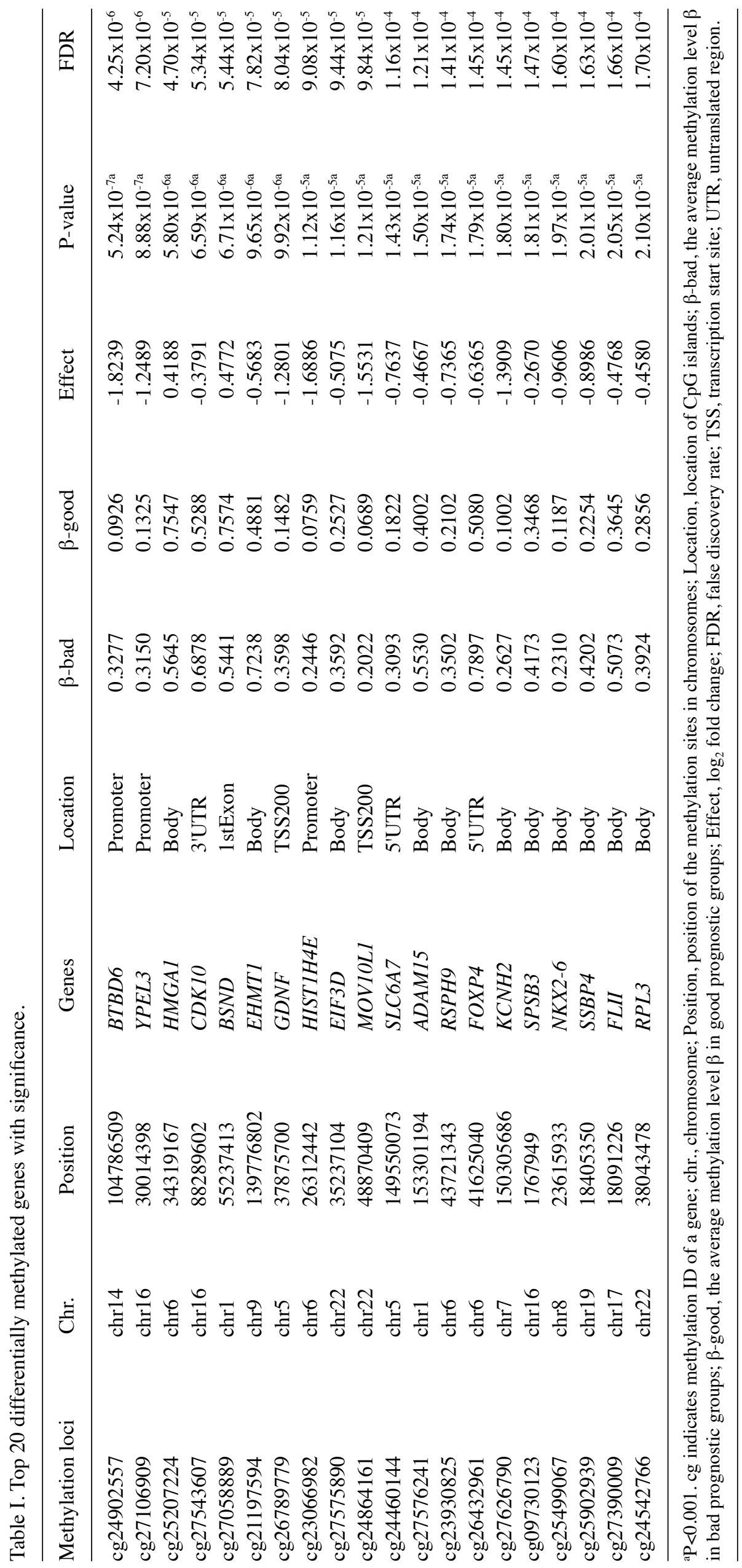


Table II. A total of 10 modules identified by weighted gene co-expression network analysis.

\begin{tabular}{|c|c|c|c|c|c|c|}
\hline Modules & Count of CpGs & Correlation & $\mathrm{P}_{\text {corr }}$ & DMGs & Enrichment fold (95\% CI) & $\mathrm{P}_{\text {hyper }}$ \\
\hline Black & 159 & 0.703 & $1.01 \times 10^{-13}$ & 90 & $3.481(2.622-4.599)$ & $2.20 \times 10^{-16}$ \\
\hline Blue & 427 & 0.587 & $1.68 \times 10^{-4}$ & 63 & $0.908(0.676-1.202)$ & $5.37 \times 10^{-1}$ \\
\hline Brown & 364 & 0.551 & $2.23 \times 10^{-3}$ & 10 & $0.169(0.0799-0.317)$ & $4.83 \times 10^{-13}$ \\
\hline Green & 352 & 0.616 & $6.05 \times 10^{-2}$ & 12 & $0.209(0.107-0.374)$ & $3.49 \times 10^{-11}$ \\
\hline Grey & 574 & 0.226 & $1.32 \times 10^{-1}$ & 48 & $0.514(0.371-0.701)$ & $5.31 \times 10^{-6}$ \\
\hline Magenta & 90 & 0.729 & $9.47 \times 10^{-16}$ & 23 & $1.572(0.941-2.529)$ & $7.38 \times 10^{-2}$ \\
\hline Pink & 138 & 0.679 & $1.44 \times 10^{-8}$ & 6 & $0.267(0.0961-0.601)$ & $2.88 \times 10^{-4}$ \\
\hline Red & 191 & 0.308 & $6.69 \times 10^{-7}$ & 1 & $0.0322(0.000814-0.182)$ & $3.26 \times 10^{-11}$ \\
\hline Turquoise & 1344 & 0.687 & $1.72 \times 10^{-6}$ & 394 & $1.803(1.564-2.077)$ & $4.11 \times 10^{-16}$ \\
\hline Yellow & 359 & 0.609 & $4.27 \times 10^{-6}$ & 3 & $0.0514(0.0105-0.152)$ & $2.20 \times 10^{-16}$ \\
\hline
\end{tabular}

DMGs, differentially methylated genes; CI, confidence interval; $\mathrm{P}_{\text {corr }}, \mathrm{P}$-value for correlation; $\mathrm{P}_{\text {hyper }}, \mathrm{P}$-value for hypermethylation.
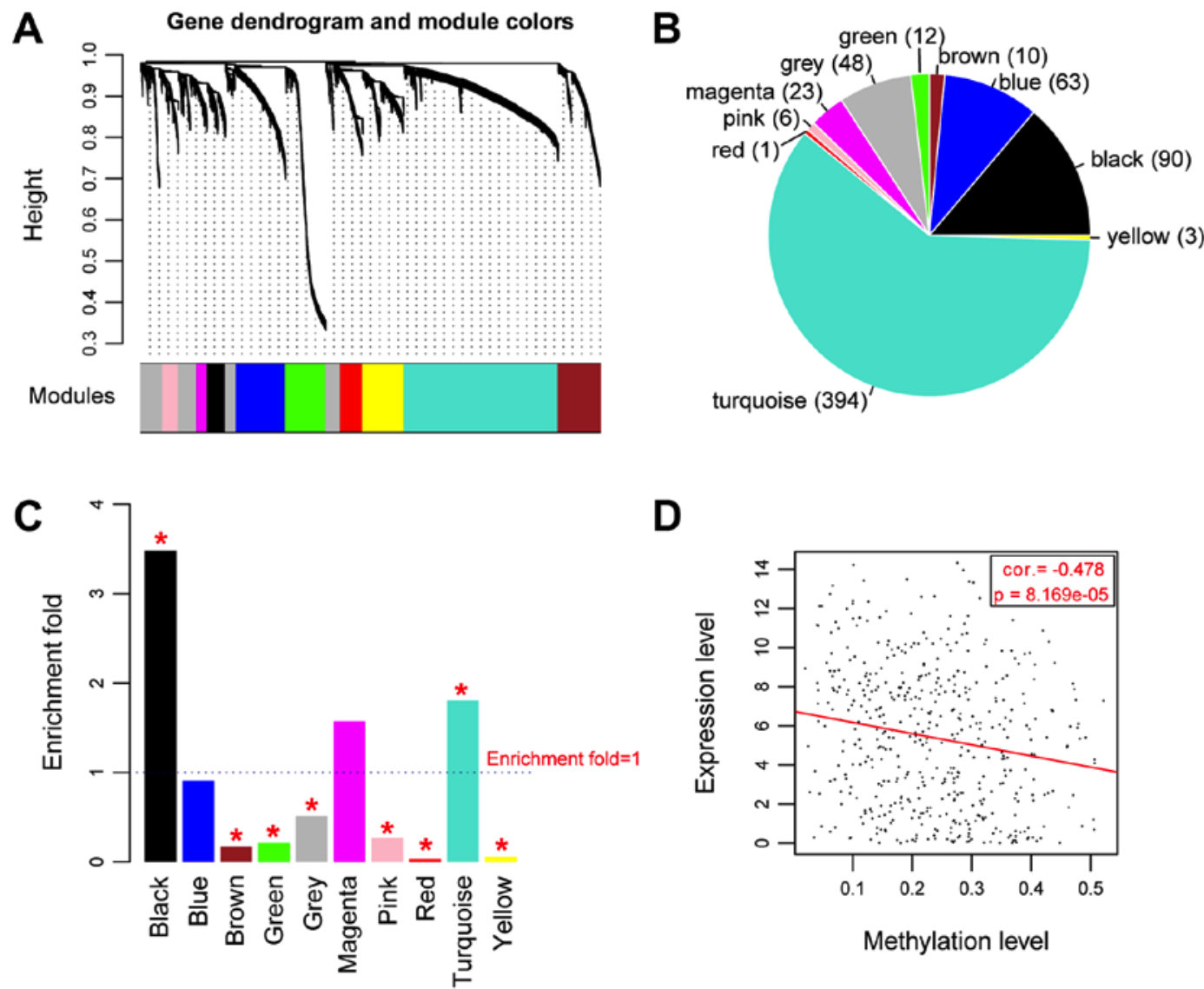

D

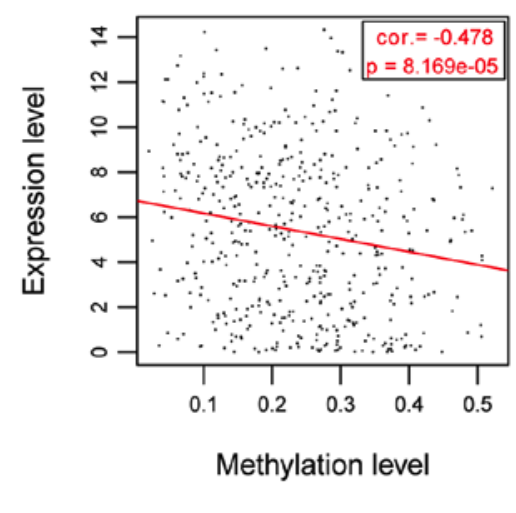

Figure 2. Results of Weighted Gene Co-expression Network Analysis. (A) Module partition tree. (B) Mapping results of the DMGs into the identified modules. Numbers in the brackets represent genes in this module. (C) Histogram of fold enrichment of the modules. (D) Scatter diagram showing the overall correlation between the methylation levels and expression levels of the 484 DMGs. Red line, trend line of point distribution. "Represents the modules with significantly enriched methylated genes $(\mathrm{P}<0.05)$. DMGs, differentially methylated genes; cor., correlation coefficient.

Identification of co-methylated genes based on WGCNA. A total of 10 modules were identified (Fig. 2A) and the detailed information of each module is listed in Table II. CpG island genes in 9 modules showed significant a association with methylation levels $(\mathrm{P}<0.05$; correlation coefficients, 0.226-0.729; average correlation coefficient, 0.7742 ; Table II). The identified DMGs were mapped into each module and their distribution in the modules is shown in Fig. 2B. Two modules were identified as differentially expressed $\mathrm{CpG}$ gene enriched modules, black module (comprised of 90 DMGs) and the turquoise module (comprised of 394 DMGs), in which the $\mathrm{CpG}$ genes were significantly associated with methylations. The DMGs in these two modules were significantly enriched in 18 GO_Biology Process (BP; such as 'neuron differentiation'), 7 GO_cellular 
Table III. Functional terms enriched for the 484 differentially methylated genes involved in black or turquoise modules.

A, Biological process

\begin{tabular}{|c|c|c|c|}
\hline Term & Count & P-value & FDR \\
\hline GO:0030182-neuron differentiation & 40 & $1.79 \times 10^{-10 \mathrm{a}}$ & $3.13 \times 10^{-7}$ \\
\hline GO:0006355-regulation of transcription, DNA-dependent & 95 & $4.27 \times 10^{-10 a}$ & $7.45 \times 10^{-7}$ \\
\hline GO:0051252-regulation of RNA metabolic process & 96 & $6.29 \times 10^{-10 a}$ & $1.10 \times 10^{-6}$ \\
\hline GO:0007423-sensory organ development & 27 & $1.46 \times 10^{-9 a}$ & $2.55 \times 10^{-6}$ \\
\hline GO:0007389-pattern specification process & 28 & $8.94 \times 10^{-9 a}$ & $1.56 \times 10^{-5}$ \\
\hline GO:0045165-cell fate commitment & 20 & $1.20 \times 10^{-8 a}$ & $2.10 \times 10^{-5}$ \\
\hline GO:0048568-embryonic organ development & 22 & $1.59 \times 10^{-8 \mathrm{a}}$ & $2.77 \times 10^{-5}$ \\
\hline GO:0048598-embryonic morphogenesis & 28 & $1.66 \times 10^{-7 a}$ & $2.90 \times 10^{-4}$ \\
\hline GO:0007267-cell-cell signaling & 40 & $9.79 \times 10^{-7 a}$ & $1.71 \times 10^{-3}$ \\
\hline GO:0006928-cell motion & 34 & $1.66 \times 10^{-6 \mathrm{a}}$ & $2.90 \times 10^{-3}$ \\
\hline GO:0045449-regulation of transcription & 111 & $2.63 \times 10^{-6 a}$ & $4.60 \times 10^{-3}$ \\
\hline GO:0003002-regionalization & 20 & $3.02 \times 10^{-6 a}$ & $5.27 \times 10^{-3}$ \\
\hline GO:0007610-behavior & 33 & $3.54 \times 10^{-6 a}$ & $6.18 \times 10^{-3}$ \\
\hline GO:0048666-neuron development & 27 & $3.76 \times 10^{-6 a}$ & $6.57 \times 10^{-3}$ \\
\hline GO:0031328-positive regulation of cellular biosynthetic process & 42 & $4.11 \times 10^{-6 \mathrm{a}}$ & $7.17 \times 10^{-3}$ \\
\hline GO:0009891-positive regulation of biosynthetic process & 42 & $5.85 \times 10^{-6 \mathrm{a}}$ & $1.02 \times 10^{-2}$ \\
\hline GO:0016477-cell migration & 23 & $1.16 \times 10^{-5 a}$ & $2.02 \times 10^{-2}$ \\
\hline GO:0019226-transmission of nerve impulse & 26 & $1.97 \times 10^{-5 a}$ & $3.45 \times 10^{-2}$ \\
\hline
\end{tabular}

B, Cellular component

\begin{tabular}{|c|c|c|c|}
\hline Term & Count & P-Value & FDR \\
\hline GO:0005887-integral to plasma membrane & 59 & $9.12 \times 10^{-7 a}$ & $1.21 \times 10^{-3}$ \\
\hline GO:0031226 intrinsic to plasma membrane & 59 & $1.89 \times 10^{-6 a}$ & $2.50 \times 10^{-3}$ \\
\hline GO:0044459-plasma membrane part & 90 & $2.93 \times 10^{-6 a}$ & $3.88 \times 10^{-3}$ \\
\hline GO:0034703-cation channel complex & 15 & $6.78 \times 10^{-6 a}$ & $8.98 \times 10^{-3}$ \\
\hline GO:0034705-potassium channel complex & 12 & $1.11 \times 10^{-5 a}$ & $1.48 \times 10^{-2}$ \\
\hline GO:0008076-voltage-gated potassium channel complex & 12 & $1.11 \times 10^{-5 a}$ & $1.48 \times 10^{-2}$ \\
\hline GO:0034702-ion channel complex & 18 & $1.99 \times 10^{-5 a}$ & $2.64 \times 10^{-2}$ \\
\hline
\end{tabular}

C, Molecular function

\begin{tabular}{|c|c|c|c|}
\hline Term & Count & P-value & FDR \\
\hline GO:0043565-sequence-specific DNA binding & 58 & $4.65 \times 10^{-16 a}$ & $6.55 \times 10^{-13}$ \\
\hline GO:0003700-transcription factor activity & 74 & $4.42 \times 10^{-15 a}$ & $6.52 \times 10^{-12}$ \\
\hline GO:0030528-transcription regulator activity & 85 & $3.53 \times 10^{-10 a}$ & $5.18 \times 10^{-7}$ \\
\hline GO:0003677-DNA binding & 109 & $2.11 \times 10^{-8 a}$ & $3.09 \times 10^{-5}$ \\
\hline GO:0022836-gated channel activity & 25 & $6.95 \times 10^{-6 a}$ & $1.02 \times 10^{-2}$ \\
\hline GO:0005261-cation channel activity & 23 & $1.01 \times 10^{-5 \mathrm{a}}$ & $1.48 \times 10^{-2}$ \\
\hline GO:0015267-channel activity & 29 & $1.41 \times 10^{-5 a}$ & $2.07 \times 10^{-2}$ \\
\hline GO:0022803-passive transmembrane transporter activity & 29 & $1.48 \times 10^{-5 \mathrm{a}}$ & $2.18 \times 10^{-2}$ \\
\hline GO:0005216-ion channel activity & 27 & $3.37 \times 10^{-5 a}$ & $4.94 \times 10^{-2}$ \\
\hline
\end{tabular}

${ }^{a} \mathrm{P}<0.001$. GO, gene ontology; FDR, false discovery rate.

component (CC; such as 'integral to plasma membrane'), and 9 GO_molecular function (MF; such as 'sequence-specific DNA binding') terms (Table III) and were predominantly associated with transcriptional regulation. 
Table IV. Information of the 12 optimal genes.

\begin{tabular}{|c|c|c|c|c|c|c|c|}
\hline Methylation ID & Gene & Chr. & Position & Location & Coefficient & Hazard ratio & P-value \\
\hline $\operatorname{cg} 22250546$ & CEBPA & $\operatorname{chr} 19$ & 38483210 & Promoter & -0.4701559 & 0.197 & $2.01 \times 10^{-2 a}$ \\
\hline $\operatorname{cg} 23066982$ & HISTIH4E & chr6 & 26312442 & Promoter & 1.461097 & 1.228 & $4.11 \times 10^{-2 a}$ \\
\hline $\operatorname{cg} 23264429$ & STAMBPL1 & $\operatorname{chr} 10$ & 90631983 & 5'UTR & -0.1543761 & 0.369 & $4.53 \times 10^{-2 a}$ \\
\hline $\operatorname{cg} 25509871$ & PLD3 & $\operatorname{chr} 19$ & 45563397 & 5'UTR & 0.2124921 & 1.082 & $4.40 \times 10^{-2 a}$ \\
\hline $\operatorname{cg} 25827255$ & CEP55 & $\operatorname{chr} 10$ & 95246749 & Promoter & -0.7063513 & 0.129 & $2.04 \times 10^{-2 \mathrm{a}}$ \\
\hline $\operatorname{cg} 25902939$ & SSBP4 & $\operatorname{chr} 19$ & 18405350 & Body & 0.1268035 & 1.139 & $4.45 \times 10^{-2 \mathrm{a}}$ \\
\hline $\operatorname{cg} 26343183$ & GRIAI & $\operatorname{chr} 5$ & 152988914 & Body & -2.4642526 & 0.276 & $1.33 \times 10^{-2 \mathrm{a}}$ \\
\hline $\operatorname{cg} 26645401$ & SWAP70 & $\operatorname{chr} 11$ & 9643090 & Body & -0.4583647 & 0.272 & $2.02 \times 10^{-2 \mathrm{a}}$ \\
\hline $\operatorname{cg} 27076139$ & $A D C Y A P 1 R 1$ & $\operatorname{chr} 7$ & 31058243 & TSS1500 & 0.0652014 & 1.014 & $1.35 \times 10^{-2 \mathrm{a}}$ \\
\hline $\operatorname{cg} 27106909$ & YPEL3 & chr16 & 30014398 & Promoter & 0.2566994 & 1.294 & $4.32 \times 10^{-2 \mathrm{a}}$ \\
\hline $\operatorname{cg} 27138204$ & $\mathrm{HOXC4}$ & $\operatorname{chr} 12$ & 52732367 & 5'UTR & 0.7707755 & 1.679 & $1.58 \times 10^{-2 \mathrm{a}}$ \\
\hline $\operatorname{cg} 27447599$ & $I G F B P 1$ & chr7 & 45894465 & TSS200 & 0.172493 & 1.193 & $2.18 \times 10^{-2 a}$ \\
\hline
\end{tabular}

${ }^{\mathrm{a}} \mathrm{P}<0.01$. chr, chromosome; coef, correlation coefficient; UTR, untranslated region; TSS, transcription start site.
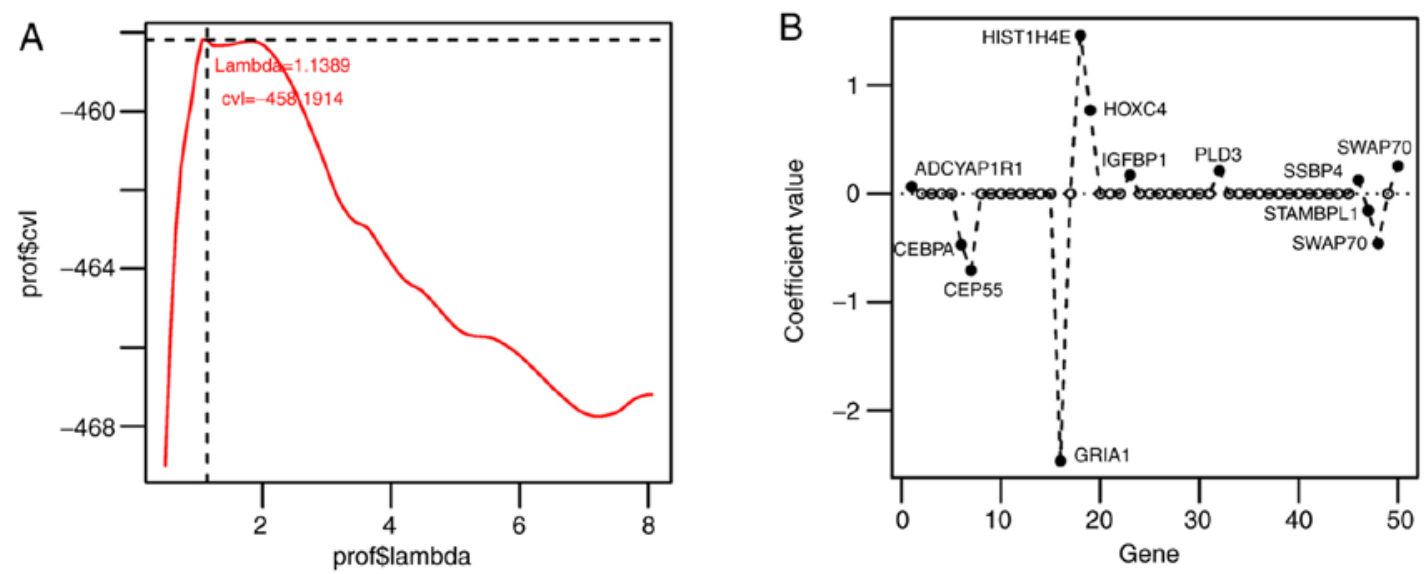

Figure 3. Selection curve and coefficient distribution diagram. (A) Selection curve of lambda (the junction indicates that the maximum value of cvl is - 458.1914 when $\lambda=1.1389$ ) (B) The coefficient distribution diagram of the genes implicated in the optimal gene combination.cvl, cross validation likelihood; prof $\$$ in Y-axis indicated the $\mathrm{p}$ value using the predictive model, and in X-axis indicated the lambda value using the predictive model; CEBPA, CCAAT/enhancer binding protein $\alpha$; HIST1H4E, histone cluster 1 H4E; STAMBPL1, STAM binding protein-like 1; PLD3, phospholipase D3; CEP55, centrosomal protein 55; SSBP4, ssDNA binding protein 4; GRIA1, glutamate AMPA receptor subunit 1; SWAP70, switch-associated protein 70; ADCYAP1R1, adenylate-cyclase activating polypeptide 1 receptor 1; YPEL3, yippee-like 3; HOXC4, homeobox C4; IGFBP1, insulin-like growth factor binding protein 1.

Correlation analysis of the expression levels and methylation levels of key methylated genes. Overall, the methylation levels and expression levels of the 484 DMGs in the black and turquoise modules were significantly negatively correlated (Cor.=-0.478, P=8.169 $\times 10^{-5}$; Fig. 2D). A total of $192 \mathrm{DMGs}$ exhibited negative correlation between the expression levels and methylation levels (Table SI).

Construction of the risk score system. A total of 50 genes among the 192 DMGs were found to be associated with prognosis. Following this, a Cox-PH model was utilized to screen the optimal gene combination. When $\lambda=1.1389$, the maximum value of cvl was obtained as -458.1914 (Fig. 3A). Using $\lambda=1.1389$, a 12-gene optimal combination was acquired: CCAAT/enhancer binding protein $\alpha(C E B P \alpha)$; histone cluster 1 H4E (HIST1H4E); STAM binding protein-like 1, (STAMBPL1) phospholipase D3 (PLD3); centrosomal protein
55 (CEP55); ssDNA binding protein 4 (SSBP4); glutamate AMPA receptor subunit 1 (GRIAl); switch-associated protein 70 (SWAP70); adenylate-cyclase activating polypeptide 1 receptor 1 (ADCYAPIR1); yippee-like 3 (YPEL3); homeobox $\mathrm{C} 4$ (HOXC4); and insulin-like growth factor binding protein 1 (IGFBPI) (Fig. 3B; Table IV). Combined with the prognostic coefficients of these 12 optimal genes, the following risk score system was constructed (cg is the methylation ID for corresponding genes.).

Risk score $=(-0.4701559) \times$ Methylation ${ }_{\operatorname{cg} 22250546}+$ (1.461097) x Methylation ${ }_{\mathrm{cg} 23066982}+(-0.1543761) \times$ Methylation ${ }_{\mathrm{cg} 23264429}+(0.2124921) \times$ Methylation ${ }_{\mathrm{cg} 25509871}+(-0.7063513)$ x Methylation ${ }_{\mathrm{cg} 25827255}+(0.1268035) \times$ Methylation $_{\mathrm{cg} 25902939}$ $+(-2.4642526) \times$ Methylation ${ }_{\mathrm{cg} 26343183}+(-0.4583647) \mathrm{x}$ Methylation $\left.{ }_{\mathrm{cg} 26645401}+(0.0652014)\right)^{x}$ Methylation ${ }_{\mathrm{cg} 27076139}+$ $(0.2566994) \times$ Methylation ${ }_{\mathrm{cg} 27106909}+(0.7707755) \times$ Methylation $\mathrm{cg}_{27138204}+(0.172493) \times$ Methylation cg27447599. $_{\text {. }}$ 


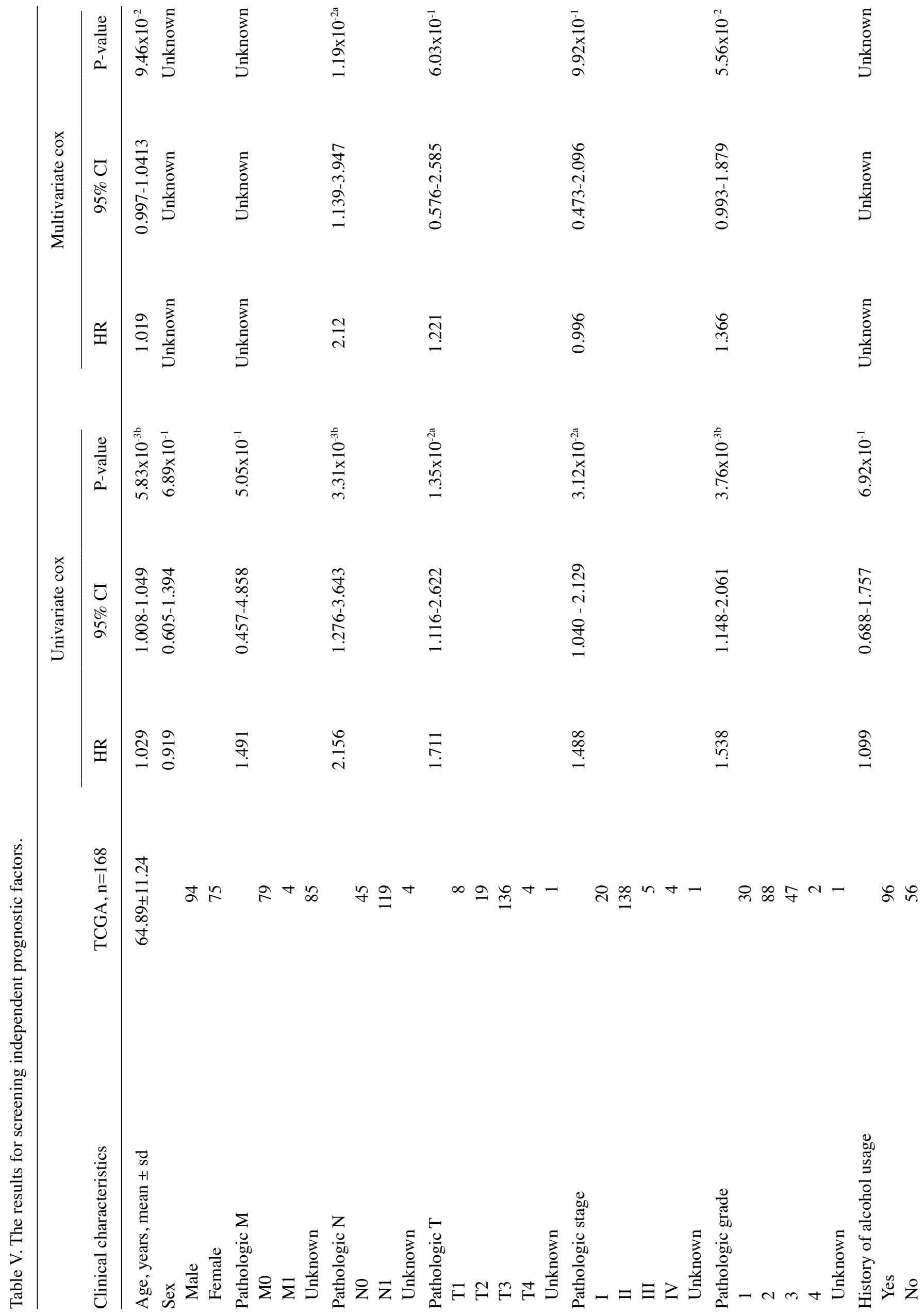




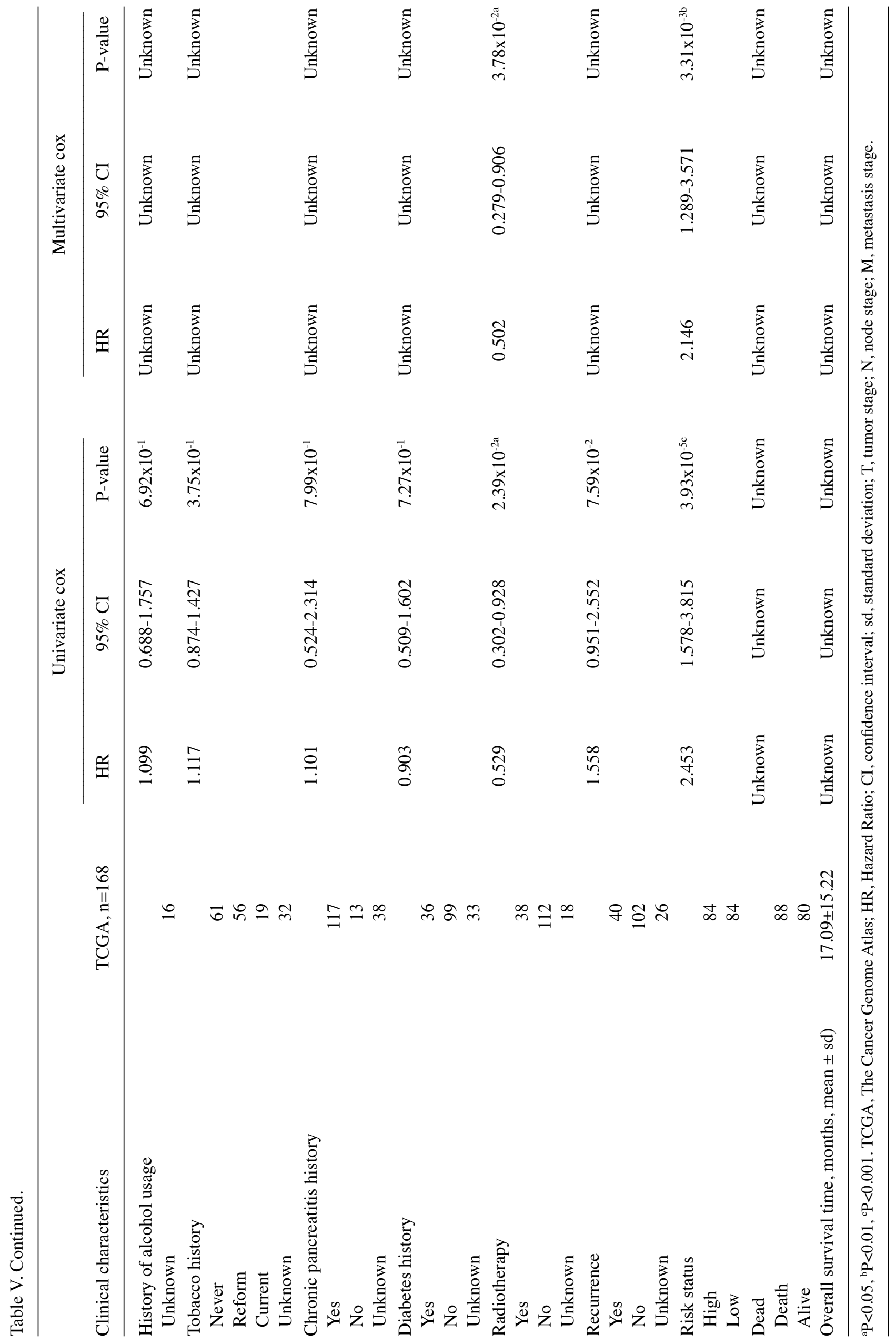



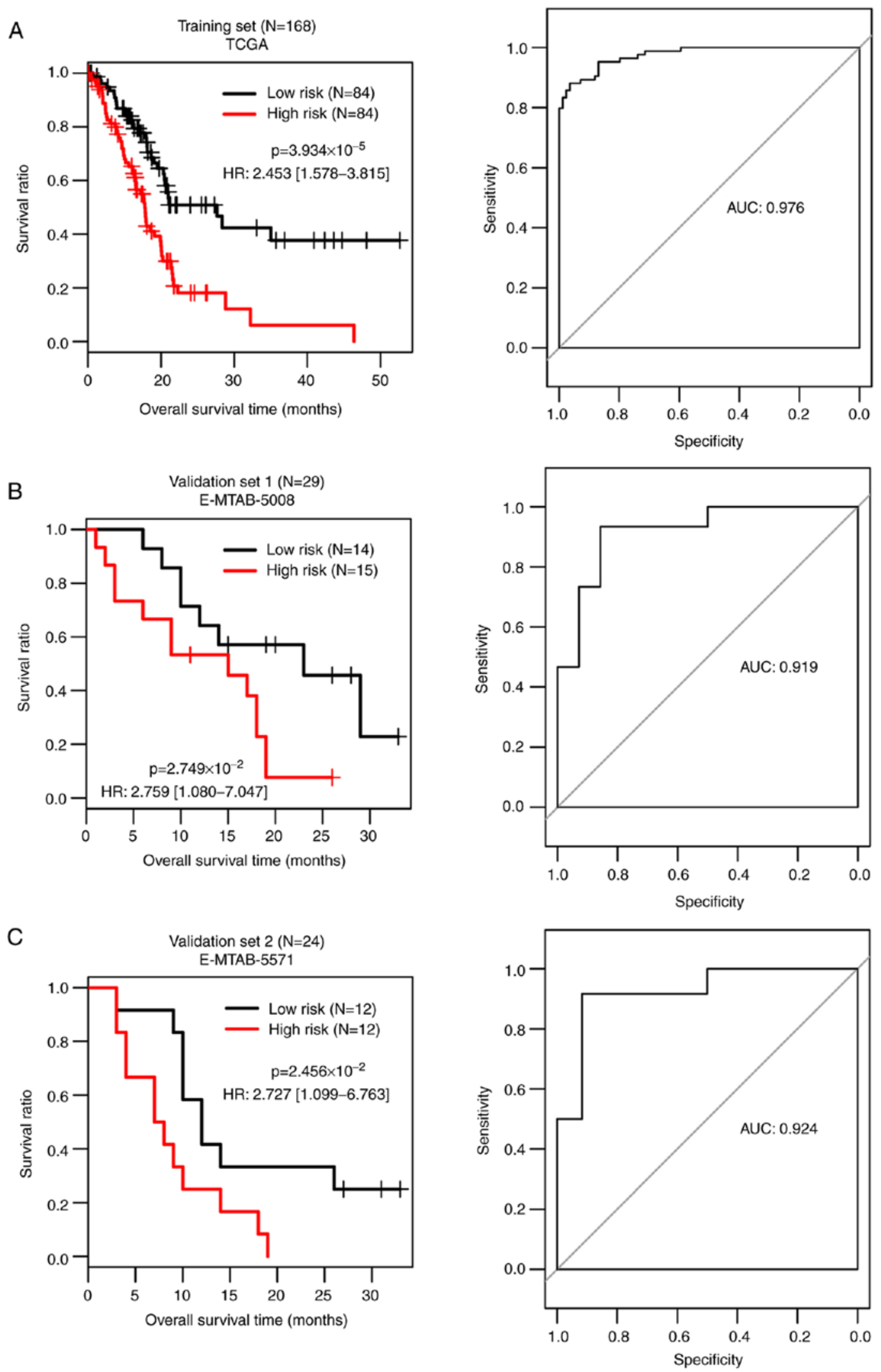

Figure 4. KM curves and AUC under the ROC curve. (A) KM curve (left) and ROC curve (right) for TCGA dataset. (B) KM curve (left) and ROC curve (right) for E-MTAB-5008 dataset. (C) KM curve (left) and ROC curve (right) for E-MTAB-5571 dataset. KM, Kaplan-Meier; HR, hazard ratio; TCGA, The Cancer Genome Atlas; ROC, receiver operating characteristic; AUC, area under the curve.

According to the median of the risk scores of the samples in the TCGA dataset, the samples were divided into high and low risk groups. For the TCGA dataset, the comparison between the actual overall survival and risk score system predicting survival of the risk groups was performed and the AUC was 0.976 (Fig. 4A). Moreover, the risk score system was validated 
A

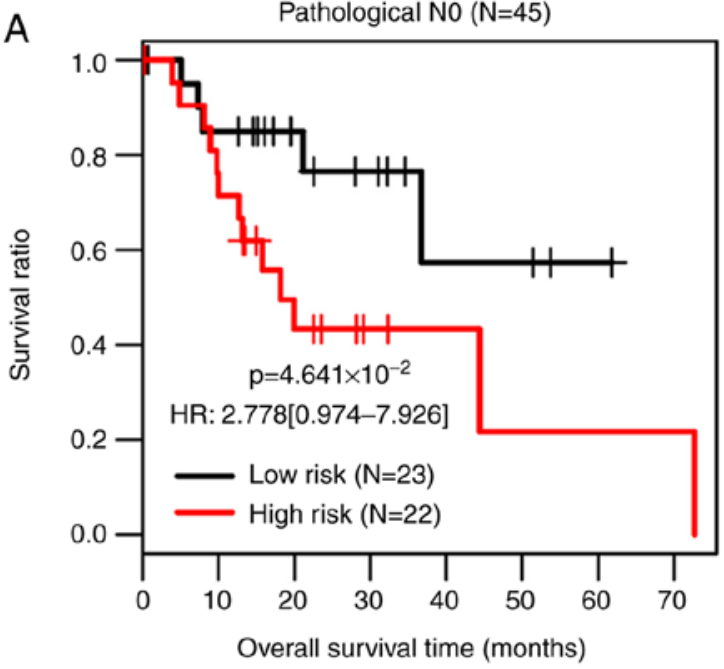

B

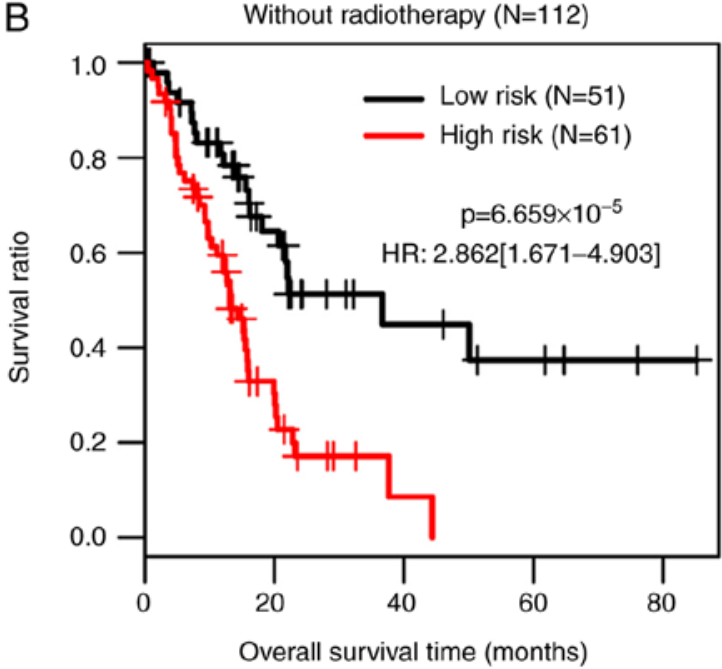

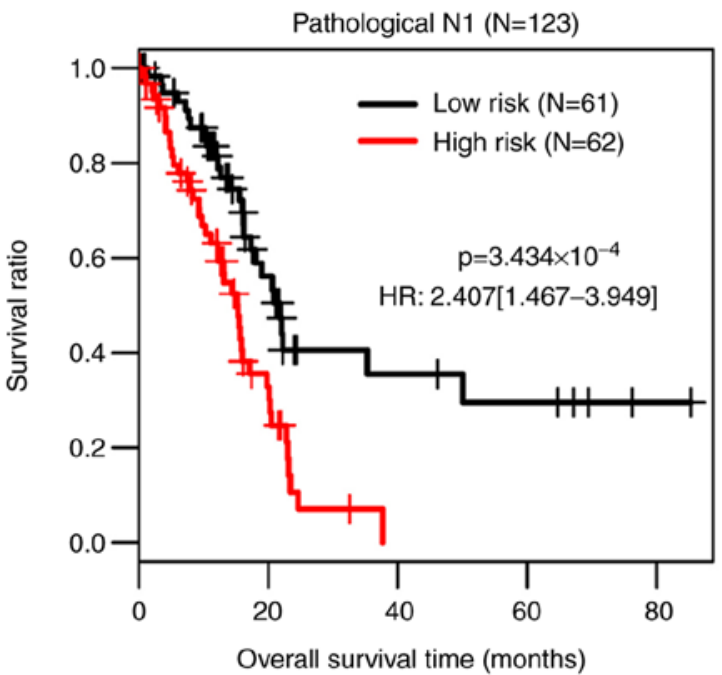

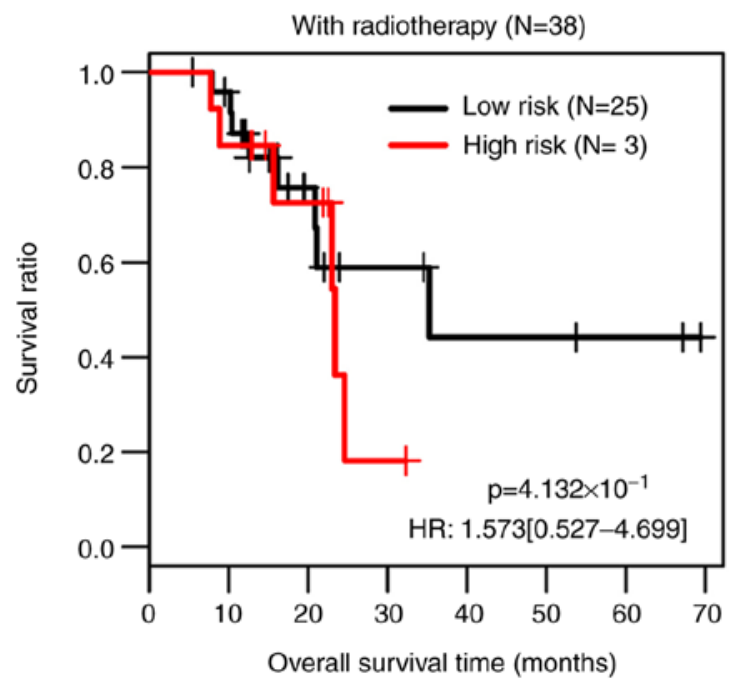

Figure 5. KM curves for high- and low-risk groups with different TNM stages and radiotherapy treatment status. (A) KM curves showing the correlations of pathological N0 (left) and pathological N1 (right) with risk groups. (B) KM curves showing the correlations between without radiotherapy (left) or with radiotherapy (right) and risk groups. KM, Kaplan-Meier; HR, hazard ratio; T, tumor stage; N, node stage; M, metastasis stage.

in the E-MTAB-5008 (Fig. 4B) and E-MTAB-5571 (Fig. 4C) datasets and the AUCs were 0.919 and 0.924, respectively. The TCGA, E-MTAB-5008 and E-MTAB-5571 datasets had consistent results and all the samples in low risk group had improved survival.

Correlation analysis between independent prognostic factors and risk groups. The clinical information of 168 samples in the TCGA dataset was statistically analyzed, and pathological tumor-node-metastases (TNM) staging system (36), radiotherapy and risk status were identified as independent prognostic factors (Table V). Survival status of high and low risk groups with different pathological N stages (N0 vs. N1) and treatment with radiotherapy (treatment with radiotherapy vs. without radiotherapy) were compared (Fig. 5).

\section{Discussion}

The mechanisms underlying tumor development and progression of PAAD are complex, and influencing factors include epigenetic regulation of gene expression, epigenetic silencing of genes, oncogenic/tumor suppressor gene mutation, telomere alteration, genomic instability and DNA methylation (37-40). The present study aimed to identify potential important key methylated genes in PAAD. A total of 1,067 DMGs were identified in the less favorable prognosis and more favorable prognosis groups. From the 10 modules identified by WGCNA, the black (involving 90 DMGs) and turquoise (involving 394 DMGs) modules, in which the $\mathrm{CpG}$ genes were significantly associated with methylations, were selected for further analysis. For the 484 DMGs involved in the two key modules, 18 GO_BP, 7 GO_CC and 9 GO_MF terms were enriched. There were 192 DMGs associated with prognosis (less favorable or more favorable). Correlation analysis indicated that the expression levels and methylation levels of 192 DMGs among the 484 DMGs were negatively correlated. Furthermore, 50 prognosis-associated genes were further screened from the 192 DMGs. After a 12-gene optimal combination (CEBPA, HIST1H4E, STAMBPL1, PLD3, CEP55, SSBP4, GRIA1, SWAP70, ADCYAP1R1, YPEL3, HOXC4 and IGFBPI) was identified, the risk score system was constructed and validated in the TCGA, E-MTAB-5008 and E-MTAB-5571 datasets. In 
addition, pathological $\mathrm{N}$ category, radiotherapy and risk status were found to be independent prognostic factors.

It is demonstrated that upregulation of CCAAT/enhancer binding protein $(\mathrm{C} / \mathrm{EBP})$ beta $(\mathrm{C} / \mathrm{EBP} \beta)$, encoded by $C E B P B$, could restore the anti-cancer functions of Menin in PC (41) The inadequate cytoplasmic localization and abnormal silencing of $C / E B P$ results in its dysfunction, and thus, $C / E B P$ may serve as a novel suppressor in PC cells (42). Downregulated $C / E B P \alpha$ induced by lysine $(\mathrm{K})$-specific demethylase 6B (KDM6B) promotes the aggressiveness of pancreatic ductal adenocarcinoma (PDAC) cells, indicating that the $K D M 6 B-C / E B P \alpha$ axis is associated with the progression of $\operatorname{PDAC}(43,44)$. Histone H3 modification affects the gene expression and promoter methylation of $M U C 2$, which may be critical for the prognostic prediction of patients with PC (45). The mRNA expression levels of histone $\mathrm{H} 4$ is lowered by polyamide-chlorambucil conjugate (1R-Chl) in the MIA PaCa-2 PC cell line and histone $\mathrm{H} 4$ genes have elevated histone acetylation in tumor cells (46). Therefore, CEBPA and HISTIH4E may be critical for the survival of PAAD patients.

STAMBPL1 affects the activation of $N F-\kappa \mathrm{B}$ through mediating the stability and localization of Tax (47) and $N F-\kappa B$ blockade can inhibit the oncogenicity and metastasis of PC cells (48). Overexpression of CEP55 can promote PC cell aggressiveness via activation of the NF- $\mathrm{\kappa B}$ pathway; therefore, CEP55 may be a prognostic factor and therapeutic target for patients with PC (49). Downregulated expression of YPEL1 in PAAD samples is associated with perineural invasion and survival prognosis, thus YPEL1 may serve a role in the malignant transformation of pancreatic tissues (50). Low IGFBPI plasma levels have a more notable influence in non-smoking patients with PC and predicts an increased risk of PC (51). These data suggest that STAMBPL1, CEP55, YPEL3 and $I G F B P 1$ may be associated with the prognosis of patients with PAAD.

Although PLD3,SSBP4,GRIA1,SWAP70 and ADCYAPIRI do not have reported associations with PAAD to the best of our knowledge, their influence on other types of human cancer have been reported. Elevated expression and activity of $P L D$ is detected in multiple types of cancer, such as gastric, colorectal, renal, stomach, lung and breast cancers (52), and $P L D$ serves a role in mediating cell proliferation, cell transition, survival signaling and tumor progression (53). $S S B P 2$ is a tumor suppressor gene and the disruption of $S S B P 2$-associated pathways may be involved in the malignant transformation of various tissues (54). GRIAl is involved in glutamate receptor signaling, which is an epigenetic marker for overall mortality rate of basal-like urothelial carcinomas (55). The oncogene $S W A P 70$ functions in regulating actin rearrangement in basal-like bladder cancer (55) and serves a role in the transformation-associated signaling pathway (56). The promoter hypermethylation level of $A D C Y A P 1$ is associated with cervical cancer development and is considered as a promising methylation marker for the early detection of cervical cancer (57). Therefore, PLD3, SSBP4, GRIA1, SWAP70 and $A D C Y A P 1 R 1$ may also be associated with the prognosis of patients with PAAD.

In the present study comprehensive bioinformatics analysis of PAAD samples was performed to identify prognosis-associated genes and to construct a risk score prognostic prediction system. All findings were obtained from relatively small-sized cohorts and thus require further experimental validation. Additionally, the patient cohort samples in the three datasets may exert different clinical features, such as disease stage, historical treatment and demographics, which should be carefully compared in further studies.

In conclusion, 1,067 DMGs were identified and a 12-gene optimal combination consisting of CEBPA, HISTIH4E, STAMBPL1, PLD3, CEP55, SSBP4, GRIA1, SWAP70, ADCYAPIRI, YPEL3, HOXC4 and IGFBPI was obtained. This 12-gene risk score prognostic prediction system may be valuable for predicting the prognosis of patients with PAAD.

\section{Acknowledgements}

Not applicable.

\section{Funding}

No funding was received.

\section{Availability of data and materials}

The datasets used and/or analyzed during the current study are available from the corresponding author on reasonable request.

\section{Authors' contributions}

DD conceived the study design and performed manuscript drafting, SY was responsible for data collection and analysis and JZ performed data interpretation and manuscript writing. All authors read and approved the final manuscript.

\section{Ethical approval and consent to participate}

Not applicable.

\section{Patient consent for publication.}

Not applicable.

\section{Competing interests}

The authors declare that they have no competing interests.

\section{References}

1. Vincent A, Herman J, Schulick R, Hruban RH and Goggins M: Pancreatic cancer. Lancet 378: 607-620, 2011.

2. Palacio S, McMurry HS, Ali R, Donenberg T, Silva-Smith R, Wideroff G, Sussman DA, Rocha Lima CMS and Hosein PJ: DNA damage repair deficiency as a predictive biomarker for FOLFIRINOX efficacy in metastatic pancreatic cancer. J Gastrointest Oncol 10: 1133-1139, 2019.

3. Rabow MW, Petzel MQB and Adkins SH: Symptom management and palliative care in pancreatic cancer. Cancer J 23: 362-373, 2017.

4. Stromnes IM and Greenberg PD: Greenberg, pancreatic cancer: Planning ahead for metastatic spread. Cancer Cell 29: 774-776, 2016.

5. Kanda M, Fujii T, Nagai S, Kodera Y, Kanzaki A, Sahin TT, Hayashi M, Yamada S, Sugimoto H, Nomoto S, et al: Pattern of lymph node metastasis spread in pancreatic cancer. Pancreas 40: 951-955, 2011. 
6. McGuire S: World Cancer Report 2014. Geneva, Switzerland: World Health Organization, International Agency for Research on Cancer, WHO press, 2015. Adv Nutr 7: 418-419, 2016.

7. Giulietti M, Righetti A, Principato G and Piva F: LncRNA co-expression network analysis reveals novel biomarkers for pancreatic cancer. Carcinogenesis 39: 1016-1025, 2018.

8. Flattet Y, Yasmaguchi T, Andrejevic-Blant S and Halkic N: Pancreatic adenocarcinoma: The impact of preneoplastic lesion pattern on survival. Biosci Trends 9: 402-406, 2015.

9. Fu YJ, Li KZ, Bai JH and Liang ZQ: C-reactive protein/albumin ratio is a prognostic indicator in Asians with pancreatic cancers: A meta-analysis. Medicine (Baltimore) 98: e18219, 2019.

10. Schlick K, Magnes T, Huemer F, Ratzinger L, Weiss L, Pichler M, Melchardt T, Greil R and Egle A: C-reactive protein and neutrophil/lymphocytes ratio: Prognostic indicator for doubling overall survival prediction in pancreatic cancer patients. J Clin Med 8: E1791, 2019.

11. Esteller M: Relevance of DNA methylation in the management of cancer. Lancet Oncol 4: 351-358, 2003.

12. Espada $\mathrm{J}$ and Esteller M: DNA methylation and the functional organization of the nuclear compartment. Semin Cell Dev Biol 21: 238-246, 2010.

13. Misawa K, Mochizuki D, Imai A, Endo S, Mima M, Misawa Y, Kanazawa T, Carey TE and Mineta H: Prognostic value of aberrant promoter hypermethylation of tumor-related genes in early-stage head and neck cancer. Oncotarget 7: 26087-26098, 2016.

14. Sato N, Fukushima N, Matsubayashi H, Iacobuzio-Donahue CA, Yeo CJ and Goggins M: Aberrant methylation of Reprimo correlates with genetic instability and predicts poor prognosis in pancreatic ductal adenocarcinoma. Cancer 107: 251-257, 2010

15. Matsubayashi H, Sato N, Fukushima N, Yeo CJ, Walter KM, Brune K, Sahin F, Hruban RH and Goggins M: Methylation of cyclin D2 is observed frequently in pancreatic cancer but is also an age-related phenomenon in gastrointestinal tissues. Clin Cancer Res 9: 1446-1452, 2003.

16. Henriksen SD, Madsen PH, Larsen AC, Johansen MB, Pedersen IS, Krarup H and Thorlacius-Ussing O: Promoter hypermethylation in plasma-derived cell-free DNA as a prognostic marker for pancreatic adenocarcinoma staging. Int J Cancer 141: 2489-2497, 2017

17. Henriksen SD, Madsen PH, Larsen AC, Johansen MB Pedersen IS, Krarup $\mathrm{H}$ and Thorlacius-Ussing O: Cell-free DNA promoter hypermethylation in plasma as a predictive marker for survival of patients with pancreatic adenocarcinoma. Oncotarget 8: 93942-93956, 2017.

18. Bournet B, Muscari F, Buscail C, Assenat E, Barthet M, Hammel P, Selves J, Guimbaud R, Cordelier P and Buscail L: KRAS G12D mutation subtype is a prognostic factor for advanced pancreatic adenocarcinoma. Clin Transl Gastroenterol 7: e157, 2016.

19. Lee B, Lipton L, Cohen J, Tie J, Javed AA, Li L, Goldstein D, Burge M, Cooray P, Nagrial A, et al: Circulating tumor DNA as a potential marker of adjuvant chemotherapy benefit following surgery for localized pancreatic cancer. Ann Oncol 30: 1472-1478, 2019.

20. Loosen SH, Tacke F, Püthe N, Binneboesel M, Wiltberger G Alizai PH, Kather JN, Paffenholz P, Ritz T, Koch A, et al: High baseline soluble urokinase plasminogen activator receptor (suPAR) serum levels indicate adverse outcome after resection of pancreatic adenocarcinoma. Carcinogenesis 40: 947-955, 2019.

21. Carreras-Torres R, Johansson M, Gaborieau V, Haycock PC Wade KH, Relton CL, Martin RM, Davey Smith G and Brennan P: The role of obesity, type 2 diabetes, and metabolic factors in pancreatic cancer: A mendelian randomization study. J Natl Cancer Inst 109, 2017.

22. Iodice $S$, Gandini S, Maisonneuve P and Lowenfels AB: Tobacco and the risk of pancreatic cancer: A review and meta-analysis. Langenbecks Arch Surg 393: 535-545, 2008.

23. Wang $\mathrm{P}$, Wang Y, Hang B, Zou X and Mao JH: A novel gene expression-based prognostic scoring system to predict survival in gastric cancer. Oncotarget 7: 55343-55351, 2016.

24. R Core Team (2012). R: A language and environment for statistical computing. R Foundation for Statistical Computing, Vienna, Austria. ISBN 3-900051-07-0, http://www.R-project.org/.

25. Wright RM, et al: Samples and traits for WGCNA. Cryobiology 71: 544,2015

26. Cao J and Zhang S: A bayesian extension of the hypergeometric test for functional enrichment analysis. Biometrics 70: 84-94, 2014

27. Balakrishnan R, Harris MA, Huntley R, Van Auken K and Cherry JM: A guide to best practices for Gene Ontology (GO) manual annotation. Database (Oxford) 2013: bat054, 2013.
28. Huang DW, Sherman BT, Tan Q, Kir J, Liu D, Bryant D, Guo Y, Stephens R, Baseler MW, Lane HC and Lempicki RA: DAVID bioinformatics resources: Expanded annotation database and novel algorithms to better extract biology from large gene lists. Nucleic Acids Res 35 (Web Server Issue): W169-W175, 2007.

29. Stadler L, et al: Optimizing R language execution via aggressive speculation. in Symposium on Dynamic Languages, 2016.

30. Zou KH, Tuncali K and Silverman SG: Correlation and simple linear regression. Radiology 227: 617-622, 2003.

31. Nadarajah S and Bakar AAS: A new R package for actuarial survival models. Computational Statistics 28: 2139-2160, 2013.

32. Goeman JJ: L1 penalized estimation in the Cox proportional hazards model. Biom J 52: 70-84, 2010.

33. Horne JS and Garton EO: Likelihood cross-validation versus least squares cross-validation for choosing the smoothing parameter in kernel home-range analysis. J Wildlife Man 70: 641-648, 2011.

34. Nagy Á, Lánczky A, Menyhárt O and Győrffy B: Validation of miRNA prognosis power in hepatocellular carcinoma using expression data of independent datasets. Sci Rep 8: 9227, 2018.

35. Wakeman CJ, Martin IG, Robertson RW, Dobbs BR and Frizelle FA: Pancreatic cancer: Management and survival. ANZ J Surg 74: 941-944, 2015.

36. Court CM and Hines OJ: The new American joint committee on cancer TNM staging system for pancreatic cancer-balancing usefulness with prognostication. JAMA Surg 153: e183629, 2018

37. Xia WX, Zhang LH and Liu YW: Weighted gene co-expression network analysis reveal six hub genes involved in and tight junction function in pancreatic adenocarcinoma and their potential use in prognosis. Genet Test Mol Biomarkers 23: 829-836, 2019.

38. Gailhouste L, Liew LC, Hatada I, Nakagama $\mathrm{H}$ and Ochiya $\mathrm{T}$ : Epigenetic reprogramming using 5-azacytidine promotes an anti-cancer response in pancreatic adenocarcinoma cells. Cell Death Dis 9: 468, 2018

39. Ali S, Cohen C, Little JV, Sequeira JH, Mosunjac MB and Siddiqui MT: The utility of SMAD4 as a diagnostic immunohistochemical marker for pancreatic adenocarcinoma, and its expression in other solid tumors. Diagn Cytopathol 35: 644-648, 2007.

40. Sahin IH, Lowery MA, Stadler ZK, Salo-Mullen E, Iacobuzio-Donahue CA, Kelsen DP and O'Reilly EM: Genomic instability in pancreatic adenocarcinoma: A new step towards precision medicine and novel therapeutic approaches. Expert Rev Gastroenteral Hepatol 10: 893-905, 2016.

41. Cheng P, Chen Y, He TL, Wang C, Guo SW, Hu H, Ni CM, Jin G and Zhang YJ: Menin coordinates C/EBP $\beta$-mediated TGF- $\beta$ signaling for epithelial-mesenchymal transition and growth inhibition in pancreatic cancer. Mol Ther Nucleic Acids 18: 155-165, 2019.

42. Kumagai T, Akagi T, Desmond JC, Kawamata N, Gery S, Imai Y, Song JH, Gui D, Said J and Koeffler HP: Epigenetic regulation and molecular characterization of C/EBPalpha in pancreatic cancer cells. Int J Cancer 124: 827-833, 2010.

43. Yamamoto K, Tateishi K, Kudo Y, Sato T, Yamamoto S, Miyabayashi K, Matsusaka K, Asaoka Y, Ijichi H, Hirata Y, et al: Loss of histone demethylase KDM6B enhances aggressiveness of pancreatic cancer through downregulation of $\mathrm{C} / \mathrm{EBP} \alpha$. Carcinogenesis 35: 2404-2414, 2014.

44. Yamamoto K, Tateishi K, Miyabayashi K, Yamamoto S, Yotaro Y, Mohri D, Asaoka Y, Ijichi H, Omata M and Koike K: Reduced Jmjd3 Expression Enhances Aggressiveness of Pancreatic Cancer Through Downregulation of C/EBP $\alpha$. Gastroenterology 140: S144, 2011.

45. Yamada N, Hamada T, Goto M, Tsutsumida H, Higashi M, Nomoto $\mathrm{M}$ and Yonezawa S: MUC2 expression is regulated by histone $\mathrm{H} 3$ modification and DNA methylation in pancreatic cancer. Int J Cancer 119: 1850-1857, 2010.

46. Jespersen C, Soragni E, James Chou C, Arora PS, Dervan PB and Gottesfeld JM: Chromatin structure determines accessibility of a hairpin polyamide-chlorambucil conjugate at histone $\mathrm{H} 4$ genes in pancreatic cancer cells. Bioorg Med Chem Lett 22: 4068-4071, 2012

47. Lavorgna A and Harhaj EW: STAMBPL1 is a deubiquitinating enzyme that regulates HTLV-I Tax subcellular localization and NF-kB activation. Retrovirology 8: 1-1, 2011.

48. Xiong HQ, Abbruzzese JL, Lin E, Wang L, Zheng L and Xie K: NF-kappaB activity blockade impairs the angiogenic potential of human pancreatic cancer cells. Int J Cancer 108: 181-188, 2004.

49. Peng T, Zhou W, Guo F, Wu HS, Wang CY, Wang L and Yang ZY: Centrosomal protein 55 activates NF-kB signalling and promotes pancreatic cancer cells aggressiveness. Sci Rep 7: 5925, 2017. 
50. Abiatari I, Kiladze M, Kerkadze V, Friess H and Kleeff J: Expression of YPEL1 in pancreatic cancer cell lines and tissues. Georgian Medical News 175: 60-62, 2009.

51. Wolpin BM, Michaud DS, Giovannucci EL, Schernhammer ES, Stampfer MJ, Manson JE, Cochrane BB, Rohan TE, Ma J, Pollak MN and Fuchs CS: Circulating insulin-like growth factor binding protein-1 and the risk of pancreatic cancer. Cancer Res 67: 7923-7928, 2007.

52. Diaz-Aragon R, Ramirez-Ricardo J, Cortes-Reynosa P, Simoni-Nieves A, Gomez-Quiroz LE and Perez Salazar E: Role of phospholipase $\mathrm{D}$ in migration and invasion induced by linoleic acid in breast cancer cells. Mol Cell Biochem 457: 119-132, 2019.

53. Foster DA and Xu L: Phospholipase D in cell proliferation and cancer. Mol Cancer Res 1: 789-800, 2003.

54. Wang Y, Klumpp S, Amin HM, Liang H, Li J, Estrov Z, Zweidler-McKay P, Brandt SJ, Agulnick A and Nagarajan L: SSBP2 is an in vivo tumor suppressor and regulator of LDB1 stability. Oncogene 29: 3044-3053, 2010.
55. Tilley SK, Kim WY and Fry RC: Analysis of bladder cancer tumor $\mathrm{CpG}$ methylation and gene expression within The Cancer Genome Atlas identifies GRIA1 as a prognostic biomarker for basal-like bladder cancer. Am J Cancer Res 7: 1850-1862, 2017.

56. Shu CL, Jing-Yang-Lai, Su LC, Chuu CP and Fukui Y: SWAP-70 A new type of oncogene. PLoS One 8: e59245, 2013.

57. Jung S, Yi L, Jeong D, Kim J, An S, Oh TJ, Kim CH, Kim CJ, Yang Y, Kim KI, et al: The role of ADCYAP1, adenylate cyclase activating polypeptide 1 , as a methylation biomarker for the early detection of cervical cancer. Oncol Rep 25: 245-252, 2011.

This work is licensed under a Creative Commons Attribution-NonCommercial-NoDerivatives 4.0 International (CC BY-NC-ND 4.0) License. 